\title{
A Model to Analyze Small and Medium Enterprises' Training Needs Related to the Internationalization
}

\author{
Federica Pascucci, Valerio Temperini, Sara Bartoloni \\ Università Politecnica delle Marche, Ancona, Italy
}

\begin{abstract}
Formal training can play a particularly important role in supporting the internationalization of small and medium enterprises (SMEs). However, the demand for education services by the latter still appears limited. This is due to known structural and cultural limits that are found widely in this type of business and to the fact that the provision of training — especially that which is funded — does not seem to address adequately SMEs' needs; in many cases, such training is not stimulating, because it is perceived as too general. In fact, SMEs do not constitute a single homogeneous group and therefore assistance needs vary among the different types of firms. So, especially in relation to internationalization, it is clear that there are important differences to consider due to the variety of approaches and ways of developing this process. In order to optimize the resources to invest in the promotion of training, there is a need to find a proper balance between providing "viable solutions for all businesses" and offering "targeted responses and tailored services". In such a context, the main objective of this paper is to identify and systematize the variables that most influence the SMEs' training needs related to internationalization by taking into account the differences among them. To this end, an empirical analysis was developed involving a significant number of Italian SMEs by using a combination of qualitative research methods. The results show the critical issues faced by the investigated firms during their internationalization process and highlight some important variables that affect their training needs: export involvement, characteristics of the product/market, characteristics of the company, exporting strategy, and human resources. Based on these variables, the writers identified clusters of firms characterized by similar needs and problems to be faced.
\end{abstract}

Keywords: small and medium enterprise (SME), internationalization, export involvement, knowledge, training needs, training services

\section{Introduction}

Internationalization has become an increasingly important driver for the survival and growth of manufacturing small and medium enterprises (SMEs). The globalization process presents numerous opportunities to expand abroad, but also it reveals a lot of challenges. In order to face the recent economic and financial crisis, particularly affecting European markets, Italian firms seek to enter markets that are more and

Federica Pascucci, assistant professor of Internet and marketing at Economics Faculty, Department of Management, Università Politecnica delle Marche, Ancona, Italy.

Valerio Temperini, assistant professor of services marketing at Economics Faculty, Department of Management, Università Politecnica delle Marche, Ancona, Italy.

Sara Bartoloni, Ph.D. student of management at Economics Faculty, Department of Management, Università Politecnica delle Marche, Ancona, Italy.

Correspondence concerning this article should be addressed to Sara Bartoloni, Piazzale Martelli 8, Ancona, 60121, Italy. 
more distant from a geographic and cultural point of view. Serving international markets appears in many cases an "obliged path", although it is very difficult to accomplish.

It is well known that companies can encounter some limitations that impede the development of international activities (Leonidou, 1995). In particular, the literature on export barriers reveals several obstacles; Morgan and Katsikeas (1997) identified strategic obstacles (e.g., lack of corporate resources, restrictions in accessing foreign markets, competition, and unfavorable currency exchange), operational obstacles (e.g., marketing-mix, difficulties related to transport and logistics, and after-sales services), informational obstacles (e.g., lack of information and knowledge about foreign market), and process-based obstacles (e.g., interaction with external persons and organizations, bureaucracy, certifications, and different language and culture). Lack of information/knowledge is one of the most relevant export barriers both in terms of frequency appearance and degree of severity. Informational barriers have a critical impact on export behavior and they are rated highly by all types of SMEs (Leonidou, 2004).

Selling abroad involves high risk, arising from a lack of knowledge of and unfamiliarity with foreign contexts. All entrant firms face a "liability of foreignness" in a target foreign country and perceive a "knowledge gap" between the knowledge possessed and that which is needed (B. Pedersen, T. Pedersen, \& Lyles, 2008). This risk can be reduced by appropriate acquisition and use of information/knowledge.

Especially for SMEs, knowledge acquisition and its application are two critical elements in order to successfully compete in foreign markets. The role of knowledge and learning in the internationalization of firms has been well recognized, both according to internationalization process theory (Johanson \& Vahlne, 1977; 1990) and international new venture research (Oviatt \& McDougall, 1994). Knowledge is a necessary driver of the firm's internationalization that facilitates the process of identifying and exploiting opportunities abroad, companies' adaptation to foreign market contexts, and their ability to deal with environmental uncertainties. Corporate investments in international markets can be encouraged when the information and knowledge gap are reduced, because the foreign context becomes more familiar and the perceived risk decreases.

In this regard, it is important to stress that the increase of knowledge can activate a virtuous circle, because more knowledge motivates a company to step up its internationalization process (Andersen, 1993; Morgan, Katsikeas, \& Vorhies, 2012; Casillas, Barbero, \& Sapienza, 2014), and this in turn increases corporate knowledge and skills. As noted by Rullani (2004), knowledge is a resource that is not consumed with its use, but rather it increases.

The literature identified different types of knowledge and different sources of knowledge (Fletcher \& Harris, 2012). Previous research has emphasized the role of experiential knowledge (Hohenthal, J. Johanson, \& M. Johanson, 2014; Hilmersson, 2012; Blomstermo, Eriksson, Lindstrand, \& Sharma, 2004; Eriksson, Johanson, Majkgård, \& Sharma, 1997; 2000; Michailova \& Wilson, 2008), but objective knowledge is also relevant, for example, Durmuşoğlu, Apfelthaler, Nayir, Alvarez, and Mughan (2012) found that objective knowledge obtained from export promotion services positively contributes to the organizational learning of firms. This is especially true for internationalization knowledge, which is a firm-specific knowledge concerning how to develop and execute an internationalization strategy in different countries. Moreover, the objective and formal knowledge make the activation of a more advanced learning process based on the experiential and tacit knowledge possible (Vignola \& Marchi, 2012). 
So, methods of information and knowledge acquisition - other than direct experience - cannot be neglected (Dutot, Bergeron, \& Raymond, 2014). In particular, involving corporate staff in training programs can be very useful in order to increase corporate skills and enhance staff motivation.

However, involvement of SMEs in training activities appears arduous. Actually, a poor match between assistance needs of companies and the programs provided often exists. This is partially due to the fact that the offering of training programs is often undifferentiated through the existing generalized approach. However, SMEs do not constitute a single homogeneous group and therefore their assistance needs are different among the different types of firms. The demand for services for internationalization depends on a set of conditions that differ from one firm to another (Cafferata \& Mensi, 1995). Thus, training services too must be tailored to fit the informational needs of specific segments. Size, industry, export experience, export strategies, and export involvement all influence the firms' informational behavior, so different training programs should be formulated in order to be beneficial and effective. In particular, export involvement directly affects the assistance needs of SMEs; exporters in the initial exporting stage are likely to have different needs from existing exporters or ones that have already been actively involved in exporting for a number of years (Freixanet, 2012; Naidu \& Rao, 1993; Diamantopoulos, Schlegelmich, \& Tse, 1993).

In such a context, this paper aims to provide an approach to the analysis of SMEs' training needs that takes into account the differences among them; in this way, more targeted and attractive training programs can be formulated. In particular, this research addresses the following questions:

(1) How should SMEs' training needs related to internationalization processes be analyzed?

(2) What are the variables to consider in the analysis?

(3) How should training services to offer be formulated, tailored to different user segments?

In order to answer these questions, a qualitative empirical research on a sample of SMEs in the Marche Region (Italy) was carried out.

The remainder of the paper is organized as follows: In the next section, a review of the literature about formal training and firms' training needs is presented; then the methodology and the findings of the research are illustrated. Some concluding remarks and implications are finally discussed chances of achieving their goals in real-life cases and provided confidence ratings in their predictions.

\section{A Literature Review}

\section{Opportunities and Limitations of Formal Training}

Involving SMEs in formal training programs is important, because it facilitates the increase of corporate skills, brings new ideas with the help of collaborators outside the organization, and enhances staff motivation. As noted by Jayawarna, Macpherson, and Wilson (2007, pp. 332-333), "formal training may provide additional benefits over informal training". In particular, the following observations can be made:

- All of the necessary knowledge and skills for the internationalization process are unlikely present and available within an organization;

- More experienced and expert individuals in the organization should be able to convey their knowledge (they should have appropriate coaching and communication skills);

- Experienced employees may not have enough time to devote to training the less-experienced employees;

- Formal training may be a valid answer to SMEs' issues when it is tailored to specific needs.

In the internationalization process, formal training could have different functions, both at the beginning 
and at a later stage of internationalization process. In companies approaching the internationalization process for the first time, training can incentivize and guide the process, avoiding common mistakes committed by unexperienced firms (e.g., presentation of inadequate products at international trade fairs, inappropriate packaging, and approximate pricing). Training programs can also support international business expansion, affecting the firm's competitiveness and its capacity to manage international interactions.

However, numerous studies showed that some structural and cultural characteristics of SMEs affect their approach to training and particularly limit their involvement in formal training.

The first issue concerns managers' lack of available time, which makes it difficult for them to participate in training programs, even if they are interested (Bager, Jensen, Nielsen, \& Larsen, 2015). In this case, e-learning appears to be an interesting solution, since it offers the advantage of training anytime and anywhere; however, SMEs encounter several obstacles during the use of this training tool (Gregori \& Temperini, 2009).

The second relevant aspect is that SMEs often do not consider training as a strategic tool, because they have no proper overall business strategy. The SMEs tend to seek instant and tailored answers to the current problems, and their approach to training tends to be ongoing. Training is perceived as a necessity at the time of real need, not before it occurs. So, it is difficult to analyze and plan training needs, also because each firm has its own preferences for certain training methods.

In fact, it is widely known that SMEs' owners/managers often think that training must be useful (Sargeant, 1996) and they need to see a clear relationship between the training offered and business needs (Vinten, 2000). For this reason, workplace training is the most appreciated method, especially in the case of SMEs' entrepreneurs and managers who have a lower educational level but also have technical and production skills (Jones, Beynon, Pickernell, \& Packham, 2013; Bager et al., 2015). As Lyons and Mattare (2011) pointed out: (a) orientation for new employees; (b) in-house, on-the-job, and experientially-grounded supervised training; and (c) skills training for one's immediate job role are common training practices in smaller businesses. The authors also underlined that, for this type of enterprise, training should be tailored, experiential, and hands-on, and they stressed the importance of owners/managers' and employees' engagement. In this sense, these researchers emphasized the scenistic method, which involves the staff of the enterprise in the creation of training materials; these latter are developed on the base of needs and problems really observed in the work activities. This approach would also more clearly identify employees' training needs.

SMEs' owners and managers tend to be pragmatic and prefer less formal training approaches (Jeffrey, Hide, \& Legg, 2010). Moreover, the recent economic crisis increases the pressure on businesses, bringing even more attention to the relationship between benefits and training costs (they are generally considered to interfere with productive activities); the difficulty of SMEs to assess the real returns of training and in particular the impact on business performance often leads to a reduction in the budget for training staff.

Furthermore, there are some limitations that are often found in relation to the offer of training that favors some skepticism and a negative perception. The offer of private training (with particular reference to so-called catalog courses) is in many cases inadequate and disappointing compared to expectations and the real needs of firms (Matlay, 2004); the lack of stimuli on the supply-side often results in SMEs being left with a latent need for training, which is not translated into an explicit demand. In many cases, the provision of training is not considered interesting or relevant for SMEs (Matlay, 1999), because it appears to be too general for them (Holden, Nabi, Gold, \& Robertson, 2006). Therefore, there is a need for a differentiated approach in this particular kind of firm (Jones, 2005). 


\section{SMEs' Training Needs Analysis}

In order to encourage SMEs' involvement in training, programs should be more oriented to satisfy their expectations in terms of relevance of the training (training opportunities directly applicable to current situations to their business) and the delivery process (location, time of day, and length of session) (Walker, Redmond, Webster, \& Le Clus, 2007). In this regard, the analysis of business needs appears to be a relevant issue, especially in the case of smaller companies, as already mentioned, where failure to meet SMEs' needs is perceived as one of the main barriers to participation in formal training (Panagiotakopoulos, 2011). Failure or incorrect analysis of needs can lead to defining training programs that respond only partially to business needs, so courses are often a stimulus to understand what might serve, instead of solving the problem, to give immediate and concrete answers (Massey, 2004).

Several authors have underlined the importance of involving SME owners and managers in the early stages of training design in order to better identify the issues in which the training could have a greater impact (Fernald, Solomon, \& Bradley, 1999; Johnston \& Loader, 2003). In this stage, the support of competent professionals is essential to avoid evaluation errors by owners and managers in their self-analysis. It can also happen that owners and managers identify training needs that are not consistent with business goals or with the resolution of certain issues; therefore, they should be guided in the process of analysis (Walker et al., 2007), trying to achieve a balance between what is perceived by corporate leadership and the evaluations of the consultant/trainer (Wong, Marshall, Alderman, \& Thwaites, 1997).

McClelland (1994) emphasized the advantages of on-site observations as a method of analysis for the identification of the skills gap (p. 7):

...it is a versatile means for obtaining both qualitative as well as quantitative feedback regarding skill/knowledge deficiencies and, in particular, training needs. Depending on the focus and goals of the observation, it should be conducted by individuals who are experienced and knowledgeable with regards to the work processes, procedures, methods, and practices being observed. Such subject matter experts (SMEs) can be found both inside as well as outside the organization. Using an internal resource is generally less costly, however they are more subject to organizational and even peer pressures than an external resource would normally be.

The on-site observations appear to provide an interesting method that can help to identify very specific needs and to respond with strongly customized programs to individual cases of intervention. However, it is difficult in reality to use this method, especially among those organizations that provide training services to a wide audience of SMEs and that aim to optimize resources. Reference is made in particular to the institutional bodies, trade associations, and other organizations which represent a significant part of the training offer and that manage important economic resources to devote to qualifying SMEs. The above method may be useful to verify and explore more deeply some aspects that might appear common to a number of target companies and could therefore be applied to certain companies identified as part of the sample.

In conclusion, this problem reveals the need to find a proper balance between the need/opportunity to provide more targeted responses and the need to involve more companies, since the SME system appears to be quite wide, especially in Italy and in the Marche Region.

\section{The Influence of Export Involvement on Firms' Training Needs}

The level of export involvement is the most widely used segmentation variable in the research on export assistance and export training needs of firms (Freixanet, 2012). The extant literature agrees that firms at 
different stages of export involvement have different competencies, resources, and strategies, so they also face different obstacles to achieving their export objectives. As a consequence, they cannot be approached with the same training program. The level of export involvement also moderates the relationship between the use of export promotion programs and export performances, the achievement of export objectives, and the export strategies employed (Francis \& Collins-Dodd, 2004).

There is not a uniquely accepted definition of export involvement, since different authors utilized different measures to identify the degree of commitment in the export activity and consequently identify different classification schemes and stages. Diamantopoulos and Inglis (1988) used the term export involvement to describe the extent to which a company is dependent upon export activity for its business and it is measured by the export intensity. In the study, they identified export staff, geographical coverage, and export assistance as characteristics that better discriminate between low and high involvement exporters: "high involvement exporters have larger numbers of export staff, serve more diverse export markets, and interact with fewer export assistance agencies" (Diamantopoulos \& Inglis, 1988, p. 57).

Different authors identified different stage models of export involvement, classifying firms in different categories ranging from non-exporters to active or regular exporters (Moini, 1998; Diamantopoulos et al., 1993; Samiee \& Walters, 2002; Francis \& Collins-Dodd, 2004). Freixanet (2012) proposed a more consistent and objective segmentation procedure, dividing companies into five stages: starting/passive exporters, regular exporters with little structure, regular exporters with a complete export structure, consolidated exporters with permanent sales establishments abroad, and multinationals with production subsidiary abroad.

Although the number of stages differs across classification schemes, the description of the evolutionary pattern of export involvement and training needs required by companies is quite similar in each study. In fact, they all agreed that a company at the beginning of the exporting process has needs, objectives, and information requirements from an assistance program that differs from a company that is already exporting in different markets. As firms increase their export involvement, it appears that issues concerning information become more important. As Crick stated,

Information assistance is required to facilitate further international transactions and to provide guidance on how these transactions can become more profitable... In addition to general market information required by managers in earlier stages of the internationalization process, there is a need for more detailed information on such things as legislation, standards etc., since these more experienced exporters already have basic knowledge gained from practical experience. (1995, p. 91)

In particular, previous studies have tried to identify how export involvement influences some aspect of the export assistance program, such as the following:

Awareness and use. The lack of awareness of training programs and export assistance appears to be more acute among firms at the beginning of their exporting process (Moini, 1998; Freixanet, 2012). So, the number of programs known and used increases with the export involvement of firms. Starting/passive exporters know and use the last numbers of programs. However, there is an overall lack of awareness in all stages of export involvement, which causes a low level of export programs use. Regarding the export education program in particular, Samiee and Walters (2002) stated that regular exporting firms are significantly more interested in export education than sporadic exporters and they also varied in terms of use and preferred means of acquiring exporting knowledge. In fact, even if on-the job training is the most important source for both sporadic and regular exporters, export information and support provided by government agencies are considered very important 
only for the first one. Sporadic exporters also place greater emphasis on college education, while conversely, regular exporters prefer seminars and short courses on exporting as a means of acquiring exporting knowledge.

Different program's needs and objectives. In the early stages, firms can use assistance to become aware of exporting opportunities and benefits and hence become motivated to export (Moini, 1998; Francis \& Collins-Dodd, 2004). So, for example, pre- or non-exporters require programs that help to motivate exporting and provide information about exporting practice and export opportunities. The objective in this stage is to enhance their knowledge and competence as exporters. As Moini (1998) suggested, this could be accomplished by encouraging and supporting gradual internationalization, starting with modest export activities directed toward foreign countries close to the domestic market.

As export involvement increases, firms not only require information about exporting, but they also need planning support (Diamantopoulos et al., 1993), training, and information to improve export competencies and assistance in identifying contacts and opportunities (Freixanet, 2012). Then, when such firms' presence in a particular foreign market is well established, for example with permanent sales or a logistics structure, firms can rely on assistance programs for entering a new market, since they already have skilled personnel in target countries. In this scenario, their use of export programs contributes to achieving the knowledge objectives, such as information and contacts that help them in the process of expanding into new markets. In the final stage, companies with the strongest commitment to internationalization have specific problems with sales effort, pricing, and information gathering (Moini, 1998), and they may need assistance conducting exporting activities, such as selling their products in export markets (Diamantopoulos et al., 1993) or requiring information about specific geographic markets (Francis \& Collins-Dodd, 2004).

Impact measure of different program use. The impact of using different groups of exporting programs varies with different levels of export involvement. Some authors (Freixanet, 2012; Francis \& Collins-Dodd, 2004) have studied these effects through the use of different impact measures. For starting/passive exporters and regular exporters with little structure, the use of direct promotion, information, assistance, and financial aid programs allowed them to improve economic performance, planning, and market diversification and to achieve marketing managers' international orientation. As the export involvement increased (regular exporters with complete structure), the use of direct promotion programs, information, or investment support programs is positively correlated with export profitability, export planning, and market diversification as well as with the creation of a sales network in the foreign markets. On the contrary, export programs and trainings have little impact on companies with the highest commitment of resources in foreign markets, since they have already internally developed the resources for internationalization. In fact, it was demonstrated that export programs impact mainly the international objectives of firms that are at the beginning and developing stages of their export activity.

The results suggest that the goals of export promotion programs and trainings are mediated by the degree of internationalization of the firms and they should be segmented accordingly. As a consequence, export programs should be tailored and carried out with a clear target audience in mind (Moini, 1998) and ultimately resolve a firms' particular marketing problem (Diamantopoulos et al., 1993). Another important issue that needs to be solved is the low level of awareness of these programs, particularly for those firms which would benefit the most, such as firms which are not exporting yet or want to increase their involvement abroad. So the providers of training programs should increase their communication efforts in order to reach their targeted audiences in a more effective manner. 
In conclusion, as emerged from the literature review, there is the need to know what the variables that most influence the SMEs' training needs related to internationalization by taking into account the differences among them are. In order to fill this gap, this paper tries to provide an approach to the analysis of SMEs' training needs which could lead to formulating more targeted and attractive training programs for firms that want to enter new international markets.

\section{Research Methodology}

The logic framework of the analysis is shown in Figure 1. The first step was the identification of firms' weak points related to internationalization. The aim of this research is not to obtain an explanation of training needs by businesses, but to identify these needs in an indirect way starting from the identification of the managerial and operational issues related to the internationalization perceived as more important by managers and entrepreneurs. The identification of these issues is the starting point from which to understand the firms' actual training needs and then to formulate effective training programs regarding the content, methods, and tools applied. In order to fulfill this objective, an empirical study is carried out in the Marche Region (central Italy), where numerous small- and medium-sized firms are disseminated.

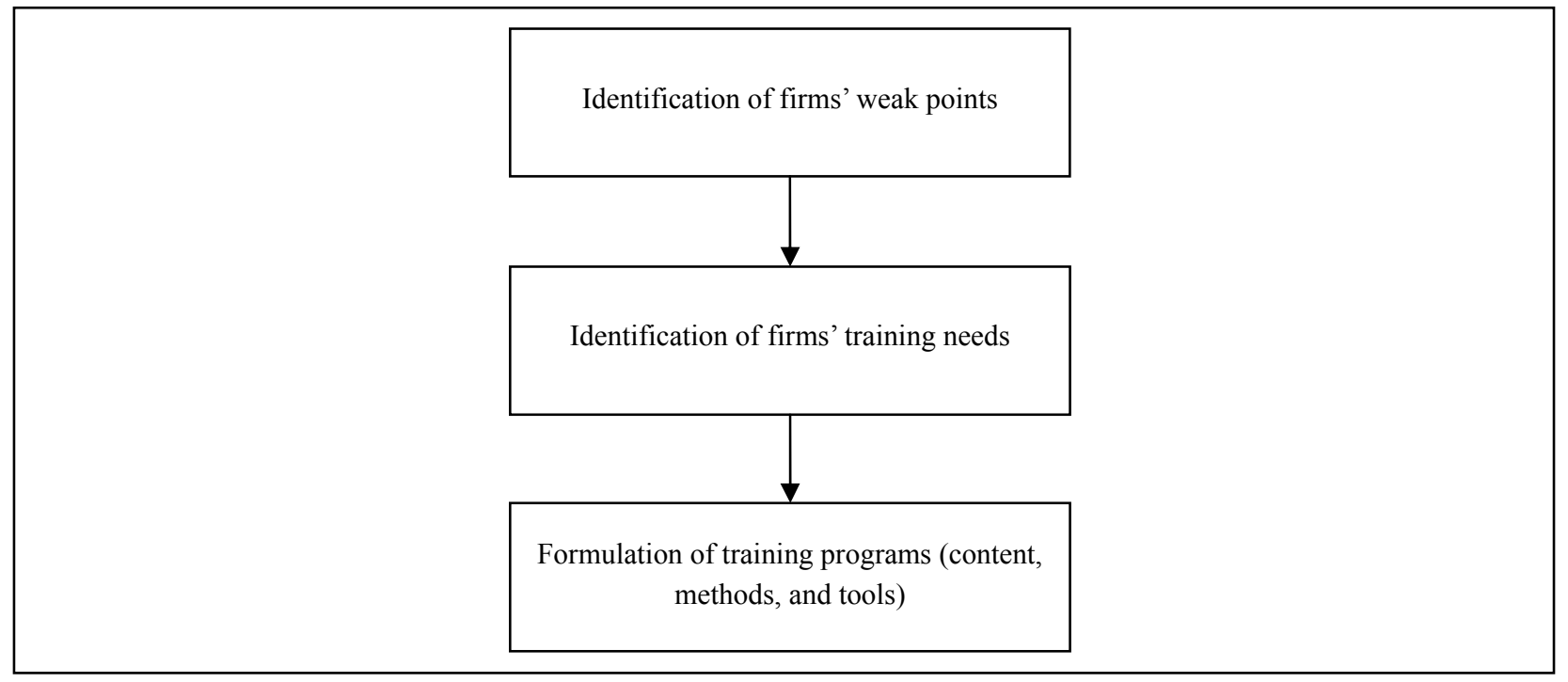

Figure 1. The logic framework of the analysis process.

In this paper, a combination of qualitative research methods is adopted. This choice was motivated by the complexity of the subject under investigation, which requires in-depth analysis in order to capture and better understand the key problems related to internationalization in light of the differences existing among the investigated firms. In particular, the following techniques are adopted:

(1) Five focus groups involving owners and managers from 42 SMEs held in each Marche's province, considering the areas of production specialization. A semi-directive approach was used; before the debate, a semi-structured questionnaire was distributed to the participants in order to stimulate early reflections on some issues and also to collect quantitative data on companies and on the investigated aspects;

(2) Multiple case studies employed by conducting several in-depth interviews to owners and managers of 29 SMEs to investigate the issues within their real contexts. Multiple case studies are a method used to identify the similarities and differences among the investigated firms (Eisenhardt, 1989; Yin, 2003). The interviews 
were conducted using a semi-structured track, but in some cases, a conversational style was adopted also encouraging storytelling approach to aid researchers to gain a greater wealth of information (Denzin \& Yvonna, 2011);

(3) Semi-structured face-to-face and telephone interviews with 23 representatives of local organizations and institutions interested in supporting internationalization processes (Chambers of Commerce, entrepreneurial associations, and export promotion agencies). These allow obtaining additional information useful to understand the context of reference, with particular attention to the experiential feedback obtained offering (directly or indirectly) support services (not just training) to the SMEs. The interaction with these organizations took place at an early stage and then progressively during the research process; integrated with the analysis of the scientific literature, the data have been useful for researchers both for setting the study and for the interpretation of the results obtained progressively from focus groups and case studies.

The enterprises of the sample were identified and contacted with the support of local entrepreneurial associations, in order to meet the representativeness criterion, from two points of view: the companies' characteristics and the productive sectors. The 71 involved firms are of different sizes, based on the number of employees as follows:

- 18 companies with less than 20 workers;

- 21 companies with 20-50 employees;

- 18 companies with 50-100 employees;

- 14 companies with more than 100 employees.

All the interviewed companies operate in the "made in Italy" sector, which includes the industries of fashion, food and wine, mechanics and automation, and wood and furniture.

The main themes investigated through focus groups and interviews are the followings:

- company profile (size, organization, ownership and management characteristics, company's offerings, and market positioning);

- relevance of the export activities for the company and export performance;

- characteristics and evolution of firms' internationalization process (also in a future perspective);

- main foreign markets served and future interests, entry strategies, organization and presence of the company in the foreign markets, and international marketing mix;

- main firm competitive drivers in the international markets;

- main problems related to the internationalization of the company and to the management of relations with the foreign markets;

- formal training experiences that the enterprise has realized, training methods most appreciated.

Given the different data collection techniques used in this paper, the analysis was performed using a combination of qualitative methods (Miles \& Huberman, 1994). In particular, a thematic analysis approach was adopted according to the deductive and inductive approach; this method is useful to summarize a large set of information, facilitating the identification and examination of the issues and the most important aspects in order to satisfy the research questions.

\section{Main Findings and Discussion: Weaknesses and Training Needs of SMEs}

In the first step of this analysis, a series of critical issues faced by the investigated firms during their internationalization process is identified: 
- Lack of or difficulty defining a long-term strategy for foreign markets (the majority of the SMEs do not realize strategic plans; their approach is often characterized by improvisation and short-term perspective);

- Lack of or limited knowledge of foreign markets (for example, product certifications, taxation, legislation, payment systems, and others are often ignored);

- No foreign language skills (in many cases, staff members do not speak English);

- Lack of knowledge of intercultural differences;

- Weaknesses in marketing communication activities;

- Inadequate knowledge of support services in the target markets offered by chambers of commerce, government offices for foreign trade, and banks;

- Limited culture in companies' aggregation (network could be a valid solution for an efficient action on foreign markets).

The above issues, which are subjects of training needs, even if present in the majority of the investigated SMEs, differ in the degree of importance and complexity, depending on the business characteristics and some variables as noted below.

The first variable to consider in the training needs analysis is the degree of export involvement. Based on what it has been said before, the writers decided to classify firms into three different groups:

A. pre-exporters;

B. sporadic exporters;

C. regular exporters - within this group it can be distinguished among the firms with high performance satisfaction from the firms with low performance satisfaction.

\section{A. Pre-exporters}

These firms have not approached foreign markets yet; they exclusively serve their domestic markets.

For this type of enterprise, training should enable the internationalization process; therefore, it is necessary to lay the basis for minimum stand trial, and in this sense, an adequate knowledge of foreign languages appears as one aspect on which to intervene. Training should also raise awareness of specific issues and relevant aspects to consider (regulations of foreign countries, management of cultural differences, marketing-mix adaptation, etc.) as well as direct business and promote a correct approach to tackle the process. Thus, the content of training programs should regard themes as follows: analysis and choice of markets, choice of entry strategies, international contracts, management of participation in international fairs, organization and management of the sales force abroad, and institutions and services to support business abroad.

\section{B. Sporadic Exporters}

These firms are characterized by limited export business, with a share of foreign sales that can comprise up to $10-20 \%$ of their turnover. In some cases, they have an intermittent approach to export. Internationalization is sporadic and there is no deliberate strategy for foreign markets.

The training may aim to promote the formulation of this strategy in order to favor a more systematic and structured approach to foreign markets in a medium-/long-term perspective. The objective can be to increase export intensity, encouraging the persistence of the action on the international markets. The themes of formal training that emerge with greater emphasis are similar to those identified for the previous cluster.

\section{Regular Exporters}

These firms are characterized by high export intensity. Within this group, two types of firms can be 
distinguished: the firms with high international performance satisfaction and the firms with low international performance satisfaction.

With regard to companies with satisfactory performance, the common objectives are to consolidate and increase the positions acquired on strategic markets and to expand into new emerging markets in order to exploit new business opportunities. Among the themes that arise with greater emphasis, the management of a more structured presence in the foreign countries (for example, the establishment of a foreign commercial or productive unit), knowledge of new emerging countries from cultural, institutional, and economic point of views, and evolution in international regulations can be noted.

Regarding the second type, the training may be aimed at improving the business presence in foreign markets, providing the tools and methodologies useful to analyze the markets and evaluate strategic options in a more effective way. In addition, training may be helpful to address the issues related to marketing and promotion in international markets. Another goal would be to improve the management of the sales force in order to facilitate penetration in the markets. Thus, the themes to develop in a formal training program are, for example, the analysis and the choice of new target markets, the choice of entry strategies and marketing-mix in these new markets, the management of the sales force, and the relationships with foreign interlocutors.

In order to organize effective training programs, it seems insufficient to distinguish firms on the basis of their export involvement, because firms with the same export involvement can have different training needs according to specific characteristics. Further segmentation of companies can be made based on other variables.

From the findings, the following significant groups of variables emerged.

(1) Product and market-related; product and market characteristics pose some unique aspects to manage. The literature review reveals that innovativeness in both products and processes influences the firm-level training intensity and the size of customer entities influences the amount of investment in training and the type of approach to training (Freel, 2005; Macpherson \& Jayawarna, 2007). The analysis confirms the relevance of the product and market variables: Training programs should be designed according to the specificities of each productive sector (such as food, mechanical equipment, and fashion) and considering the differences that exist in "B to C" and "B to B" contexts (for example, sales process, business interlocutors, and marketing-mix). Depending on the industry, specific issues can be identified, for example, international product certifications are a very important topic for food businesses.

(2) Company-related; among the firm characteristics, company size (in general measured by turnover and number of employees) is one of the most indicated variables that influence the training needs of SMEs (for example, Boocock, Loan-Clarke, Smith, \& Whittaker, 1999). As companies grow in size, also the need for training increases, because additional skills and competences are necessary. The firm's size influences the formal or informal approach to training too, with a preference for formal training in larger firms (Macpherson \& Jayawarna, 2007; Kotey \& Folker, 2007). On-the-job training is the predominant training method for SMEs of all sizes, but the adoption of formal training increases with firm size (Kotey \& Folker, 2007). The results confirm these findings. SMEs and in particular smaller-sized firms prefer training activities that allow solving real business problems. In this sense, classroom lectures do not seem to result from their interest. Especially in the case of certain issues, laboratory exercises, coaching support, and visits to other companies that represent best practices are preferable. In larger firms where an export department is often established, the training needs and approach change, with a preference for formal ones. 
Another set of variables pertains to the firm's organizational structure, such as the position of the firm's owner and the type of structure. Some studies have shown that the need of training is largely influenced by owner-manager (O’Dwyer \& Ryan, 2000); owner-managed businesses are more reluctant to invest in training, and in particular formal training, than businesses managed by non-owners (Macpherson \& Jayawarna, 2007). In more structured organizations, more importance is placed on training and on formal training (Wong et al., 1997). Also the family/non-family nature of the firm is a relevant factor, as shown by Kotey and Folker (2007).

(3) Exporting strategy-related; the findings show that the need for knowledge and expertise varies and increases when a firm develops a more stabilized presence into foreign markets (for example, sales offices, stores, showrooms, service centers, and trading company). Also, the degree of international market diversification can exercise an influence, because, depending on the number and the diversity of foreign markets into which a company is present (or intends to be present), managerial complexity increases; cultural different countries require a specific focus, because they differ in several aspects from the country of origin. Thus, even if in the same stage of export involvement, firms have different training needs depending on their export strategy, on the foreign markets served, and on their objectives (present and future).

(4) Human resources-related; the personal and cultural characteristics of corporate human resources involved in the internationalization can exercise an influence on training needs and methods (Chiva, Ghauri, \& Alegre, 2014). In particular, age, international experience, and education of decision makers (owner-manager) and staff members are significant variables.

Based on the aforementioned variables, different training needs can be identified within each of the three groups of firms; in this regard, the matrix illustrated in Table 1 can be a useful tool for insititutions during the formal training program development process.

Table 1

The Training Needs Matrix

\begin{tabular}{|c|c|c|c|c|}
\hline \multirow{2}{*}{ Segmentation variables } & \multirow{2}{*}{ Pre-exporters } & \multirow{2}{*}{ Sporadic exporters } & \multicolumn{2}{|c|}{ Regular exporter } \\
\hline & & & With high performance & With low performance \\
\hline \multicolumn{5}{|l|}{ Product-market related } \\
\hline \multicolumn{5}{|l|}{ Company related } \\
\hline \multicolumn{5}{|l|}{ Exporting strategy related } \\
\hline Human resources related & & & & \\
\hline
\end{tabular}

\section{Conclusions}

Formal training can play an important role in supporting the internationalization process of SMEs, but a gap exists between the training services offered and the actual training needs of firms. The offer of private training (with particular reference to the so-called catalog courses) is in many cases inadequate and disappointing compared to expectations and the real needs of firms (Matlay, 2004).

In order to fill this gap, a training must be developed that is more stimulating and satisfying to the expectations of SMEs; as a consequence, the analysis of training needs to become crucial.

The aim of this paper is to contribute to filling this gap and proposing a model for identifying training needs. This model presents the following two distinguishing characteristics:

- It is based on a differentiated approach to SMEs;

- It starts to identify training needs based on managerial and operational critical problems regarding the internationalization process. 
The results of empirical research permit the highlight of some important variables that affect the training needs and propose a model to facilitate a more effective analysis of the wide demand for SMEs training. Based on these variables, the writers identified clusters of firms characterized by similar needs and problems to be faced. In particular, it was noted that the three main clusters detected on the basis of the variable export involvement can be further segmented on the basis of other important variables; the scope of this further segmentation is to obtain a more precise understanding of the business's needs, and, as a result, design the content and the training methods in order to satisfy these needs in the most adequate way possible. In relation to the latter aspect, it should be underlined that, especially with reference to smaller-sized companies, a strong demand for concreteness of training interventions is confirmed; depending on the cases, this concreteness could be achieved through the exchange of operational experience and coaching in practice.

These aforementioned aspects point out that providing standard solution to the training needs of SMEs is inappropriate. The expansion in foreign markets can take place in a variety of ways and through different strategies (also depending on specific countries or markets), and companies demonstrate different cultures and organizational styles one to another. This heterogeneity calls for the development of training content, methods, and tools that can be somewhat adaptable to different situations.

From this research, important implications emerged, in particular for those public and private organizations that want to help and support the internationalization process of SMEs by providing them with the most suitable training program. In effect, the proposed model represents a useful pattern for promoting the development of more targeted training services that are consistent with SMEs' needs, and in this way, it can contribute to a more rational use of available resources that can be invested in these programs.

In addition, in order to make the training an effective support to the internationalization process of small firms, a proper culture of training must be developed, emphasizing its strategic value. SMEs tend to operate according to reactive logic, meaning that they look for immediate and operational answers to problems that arise. It follows that demand for training is rarely the result of a preventive systematic process of analysis and identification of real needs. Therefore, a culture of training must be facilitated.

The study has some limitations that present opportunities for further research:

- Although the involved sample of companies is significant for qualitative research, there may be other variables that might have escaped and could emerge instead of expanding the study;

- The proposed model should be empirically tested in order to verify if it allows for the design of effective training programs. In this sense, firms' participation rate and firms' level of satisfaction could be useful performance indicators.

\section{References}

Andersen, O. (1993). On the internationalization process of firms: A critical analysis. Journal of International Business Studies, 24(2), 209-231.

Bager, T. E., Jensen, K. W., Nielsen, P. S., \& Larsen, T. A. (2015). Enrollment of SME managers to growth-oriented training programs. International Journal of Entrepreneurial Behavior \& Research, 21(4), 578-599.

Blomstermo, A., Eriksson, K., Lindstrand, A., \& Sharma, D. D. (2004). The perceived usefulness of network experiential knowledge in the internationalizing firm. Journal of International Management, 10(3), 355-373.

Boocock, J. G., Loan-Clarke, J., Smith, A. J., \& Whittaker, J. (1999). Management training and development in small and medium-sized enterprises: An assessment of the effectiveness of Training and Enterprise Councils in the East Midlands. Journal of Small Business and Enterprise Development, 6(2), 178-190. 
Cafferata, R., \& Mensi, R. (1995). The role of information in the internationalisation of SMEs: A typological approach. International Small Business Journal, 13(3), 35-46.

Casillas, J. C., Barbero, J. L., \& Sapienza, H. J. (2015). Knowledge acquisition, learning, and the initial pace of internationalization. International Business Review, 24(1), 102-114.

Chiva, R., Ghauri, P., \& Alegre, J. (2014). Organizational learning, innovation and internationalization: A complex system model. British Journal of Management, 25(4), 687-705.

Crick, D. (1995). An investigation into the targeting of UK export assistance. European Journal of Marketing, 29(8), 76-94.

Denzin, N. K., \& Yvonna, L. (2011). The handbook of qualitative research. Thousand Oaks (CA): Sage Publications.

Diamantopoulos, A., \& Inglis, K. (1988). Identifying differences between high- and low-involvement exporters. International Marketing Review, 5(2), 52-60.

Diamantopoulos, A., Schlegelmilch, B. B., \& Tse, K. Y. (1993). Understanding the role of export marketing assistance: Empirical evidence and research needs. European Journal of Marketing, 27(4), 5-18.

Durmuşoğlu, S. S., Apfelthaler, G., Nayir, D. Z., Alvarez, R., \& Mughan, T. (2012). The effect of government-designed export promotion service use on small and medium-sized enterprise goal achievement: A multidimensional view of export performance. Industrial Marketing Management, 41(4), 680-691.

Dutot, V., Bergeron, F., \& Raymond, L. (2014). Information management for the internationalization of SMEs: An exploratory study based on a strategic alignment perspective. International Journal of Information Management, 34, 672-681.

Eisenhardt, K. (1989). Building theories from case study research. Academy of Management Review, 14(4), 532-550.

Eriksson, K., Johanson, J., Majkgård, A., \& Sharma, D. D. (1997). Experiential knowledge and cost in the internationalization process. Journal of International Business Studies, 28(2), 337-360.

Eriksson, K., Johanson, J., Majkgård, A., \& Sharma, D. D. (2000). Effect of variation on knowledge accumulation in the internationalization process. International Studies of Management \& Organization, 30(1), 26-44.

Fernald, L., Solomon, G., \& Bradley, D. (1999). Small business training and development in the United States. Journal of Small Business and Enterprise Development, 6(4), 310-325.

Fletcher, M., \& Harris, S. (2012). Knowledge acquisition for the internationalization of the smaller firm: Content and sources. International Business Review, 21, 631-647.

Francis, J., \& Collins-Dodd, C. (2004). Impact of export promotion programs on firm competencies, strategies and performance-The case of Canadian high-tech SMEs. International Marketing Review, 4(5), 474-495.

Freel, M. S. (2005). Patterns of innovation and skills in small firms. Technovation, 25(2), 123-134.

Freixanet, J. (2012). Export promotion programs: Their impact on companies' internationalization performance and competitiveness. International Business Review, 21, 1065-1086.

Gregori, G. L., \& Temperini, V. (2009). E-learning e formazione per le PMI calzaturiere: Quali nuove prospettive. Piccola Impresa/Small Business, 1, 45-70.

Hilmersson, M. (2012). Experiential knowledge types and profiles of internationalizing small and medium-sized enterprises. International Small Business Journal, 32(7), 802-817.

Hohenthal, J., Johanson, J., \& Johanson, M. (2014). Network knowledge and business-relationship value in the foreign market. International Business Review, 23(1), 4-19.

Holden, R., Nabi, G., Gold, J., \& Robertson, M. (2006). Building capability in small businesses: Tales from the training front. Journal of European Industrial Training, 30(6), 424-440.

Jayawarna, D., Macpherson, A., \& Wilson, A. (2007). Training commitment and performance in manufacturing SMEs: Incidence, intensity and approaches. Journal of Small Business and Enterprise Development, 14(2), 321-338.

Jeffrey, L. M., Hide, S., \& Legg, S. (2010). Learning characteristics of small business managers: Principles for training. Journal of Workplace Learning, 22(3), 146-165.

Johanson, J., \& Vahlne, J. E. (1977). The internationalization process of the firm-A model of knowledge development and increasing foreign market commitment. Journal of International Business Studies, 8(1), 23-32.

Johanson, J., \& Vahlne, J. E. (1990). The mechanism of internationalization. International Marketing Review, 7(4), 11-24.

Johnston, K., \& Loader, K. (2003). Encouraging SME participation in training: Identifying practical approaches. Journal of European Industrial Training, 27(6), 273-280.

Jones, J. T. (2005). The determinants of training in Australian manufacturing SMEs. Education + Training, 47(8/9), 605-615.

Jones, P., Beynon, M. J., Pickernell, D., \& Packham, G. (2013). Evaluating the impact of different training methods on SME business performance. Environment and Planning C: Government and Policy, 31(1), 56-81. 
Kotey, B., \& Folker, C. (2007). Employee training in SMEs: Effect of size and firm type-Family and nonfamily. Journal of Small Business Management, 45(2), 214-238.

Leonidou, L. C. (1995). Empirical research on export barriers: Review, assessment, and synthesis. Journal of International Marketing, 3, 29-43.

Leonidou, L. C. (2004). An analysis of the barriers hindering small business export development. Journal of Small Business Management, 42(3), 279-302.

Lyons, P., \& Mattare, M. (2011). How can very small SMEs make the time for training and development: Skill charting as an example of taking a scenistic approach. Development and Learning in Organizations: An International Journal, 25(4), 15-19.

Macpherson, A., \& Jayawarna, D. (2007). Training approaches in manufacturing SMEs. Education + Training, 49(8/9), 698-719.

Massey, C. (2004). Is the training train out of control? A case of evaluation failure from New Zealand. Journal of Small Business and Enterprise Development, 11(4), 458-466.

Matlay, H. (1999). Vocational education and training in Britain: A small business perspective. Education + Training, 41(1), 6-13.

Matlay, H. (2004). Contemporary training initiatives in Britain: A small business perspective. Journal of Small Business and Enterprise Development, 11(4), 504-513.

McClelland, S. B. (1994). Training needs assessment data-gathering methods. Journal of European Industrial Training, 18(5), 4-7.

Michailova, S., \& Wilson, H. I. M. (2008). Small firm internationalization through experiential learning: The moderating role of socialization tactics. Journal of World Business, 43, 243-254.

Miles, M. B., \& Huberman, A. M. (1994). Qualitative data analysis: An expanded sourcebook (2nd ed.). Thousand Oaks, CA: Sage.

Moini, A. H. (1998). Small firms exporting: How effective are government export assistance programs? Journal of Small Business Management, 36(1), 1-15.

Morgan, N. A., Katsikeas, C. S., \& Vorhies, D. W. (2012). Export marketing strategy implementation, export marketing capabilities, and export venture performance. Journal of the Academy of Marketing Science, 40, 271-289.

Morgan, R. E., \& Katsikeas, C. S. (1997). Obstacles to export initiation and expansion. The International Journal of Management Science, 6, 677-690.

Naidu, G. M., \& Rao, T. R. (1993). Public sector promotion of exports: A needs-based approach. Journal of Business Research, 27, 85-101.

O’Dwyer, M., \& Ryan, E. (2000). Management development issues for owners/managers of micro-entreprises. Journal of European Industrial Training, 24(6), 345-353.

Oviatt, B. M., \& McDougall, P. P. (1994). Toward a theory of international new ventures. Journal of International Business Studies, 25, 45-64.

Panagiotakopoulos, A. (2011). Barriers to employee training and learning in small and medium-sized enterprises (SMEs). Development and Learning in Organizations: An International Journal, 25(3), 15-18.

Pedersen, B., Pedersen, T., \& Lyles, M. A. (2008). Closing knowledge gaps in foreign markets. Journal of International Business Studies, 39(7), 1097-1113.

Rullani, E. (2004). Economia della conoscenza. Roma: Carocci.

Samiee, S., \& Walters, P. (2002). Export education: Perceptions of sporadic and regular exporting firms. International Marketing Review, 19(1), 80-97.

Sargeant, A. (1996). Training for growth: How can education providers assist in the development of small businesses? Industrial and Commercial Training, 28(2), 3-9.

Vignola, M., \& Marchi, G. (2012). La formazione del fabbisogno di servizi reali all'internazionalizzazione: Un modello knwledge-based. Piccola Impresa/Small Business, 1, 65-94.

Vinten, G. (2000). Training in small- and medium-sized enterprises. Industrial and Commercial Training, 32(1), 9-14.

Walker, E., Redmond, J., Webster, B., \& Le Clus, M. (2007). Small business owners: Too busy to train? Journal of Small Business and Enterprise Development, 14(2), 294-306.

Wong, C., Marshall, J. N., Alderman, N., \& Thwaites, A. (1997). Management training in small and medium-sized enterprises: Methodological and conceptual issues. International Journal of Human Resource Management, 8(1), 44-65.

Yin, R. (2003). Case study research: Design and methods (3rd ed.). Thousand Oaks, California: Sage Publication. 